\title{
Hepatic expression of miR-122 and antioxidant genes in patients with chronic hepatitis B
}

\author{
Kamila Wójcik ${ }^{\boxplus}$, Anna Piekarska', Bożena Szymańska² and Elżbieta Jabłonowska \\ 'Department of Infectious Diseases and Hepatology, Medical University of Lodz, Łódź, Poland; ${ }^{2}$ Central Laboratory, Medical University of Lodz, \\ Łódź, Poland
}

\begin{abstract}
Introduction: The pathogenesis of chronic hepatitis B depends on both, the immune response and oxidative stress. Aim of the study: To assess the hepatic expression of miR-122 and the antioxidant genes: HMOX-1, NQO1 and GFER1, in liver biopsy specimens obtained from patients with chronic hepatitis $B$, with regard to selected clinical and histological parameters, using RT-PCR. Results: The study group comprised 34 HBV-infected patients. Statistically significant associations were found between lower hepatic expression of HMOX-1 and greater severity of liver inflammation $(p=0.04)$. However, significantly higher expression of NQO1 was observed in patients with advanced liver fibrosis $(p=0.035)$. Hepatic expression of miR-122 in HBV patients was not associated with viral load or liver injury. Conclusion: The hepatic expression of HMOX-1and NQO1 may be associated with liver injuries in chronic hepatitis B. However, hepatic expression of miR-122 does not seem to correspond to progression of the liver disease.
\end{abstract}

Key words: hepatitis B, antioxidant genes, miR-122

Received: 24 November, 2015; revised: 20 April, 2016; accepted: 18 May, 2016; available on-line: 08 July, 2016

\section{INTRODUCTION}

The hepatitis B virus (HBV) has caused chronic infections in about 350 million people worldwide (WHO, 2000). Progression of the chronic hepatitis B disease is associated with an increased risk of cirrhosis, liver failure and hepatocellular carcinoma (Chen et al., 2006; Chisari et al., 2010). In addition, although HBV is not directly cytopathic towards the infected hepatocytes, the development of a chronic hepatitis B infection is associated with an inadequate immune response (Guidotti \& Chisari, 2006). Pathogenesis of the chronic hepatitis B is not only a consequence of the immune response, but also due to oxidative stress (Tasdelen Fisgin et al., 2012). Waris and coworkers reported that the HBV $\mathrm{X}$ protein induces generation of the reactive oxygen species, which could interfere with the oxidative balance of the cells (Waris et al., 2001).

Thus, cytoprotective enzymes, such as hemoxygenase (HO-1), encoded by HMOX-1 (hemeoxygenase (decycling)-1), can play a significant role in the maintenance of the cellular redox homeostasis in the course of chronic hepatitis B. HO-1 is believed to inhibit HBV replication by reducing the stability of the HBV core protein (Protzer et al., 2007; Qiu et al., 2010). Other antioxidant genes, such as NQO1 (NAD $(\mathrm{P}) \mathrm{H}$ :quinone oxidoreductase-1) and GFER1 (Growth factor erv1-like) encoding antioxidant enzymes, may also play an important role in the pathogenesis of chronic hepatitis B. Wang and coworkers (2010) note as well that micro-RNA-122 (miR-122) also decreases the HBV replication through the up-regulation of cyclin G1, which initiates the formation of a cyclin G1-p53 complex and subsequently inhibits the effect of $\mathrm{p} 53$ on HBV replication.

The aim of the study presented here was to analyse the relationship between the hepatic expression of miR-122 and antioxidant genes (HMOX-1, NQO1 (NAD(P)H:quinone oxidoreductase-1) and GFER1 (Growth factor erv1-like)) and the selected clinical and histological parameters, in liver biopsy specimens obtained from patients with chronic hepatitis B.

In addition, we attempted to determine whether the hepatic expression of HMOX-1, NQO1and GFER1 is related to the miR-122 expression.

\section{MATERIALS AND METHODS}

This study included 34 patients admitted to the Infectious Diseases and Hepatology Department, Medical University of Lodz, in the years of 2013-2014. A chronic infection with $\mathrm{HBV}$ was defined as detectable hepatitis B surface antigen and HBV DNA for over six months.

The exclusion criteria were as follows: cirrhosis (in liver biopsy), and other causes of liver diseases, like chronic hepatitis C, autoimmune hepatitis, alcohol liver disease, non-alcoholic steatohepatitis, other systemic or inflammatory diseases. Pregnant women and patients who had received concomitant medication, including antioxidant vitamin and diet supplements, within six months prior to testing, were also excluded from this analysis. This study was approved by the Ethical Committee of the Medical University of Lodz and informed written consent was obtained from every patient. The procedures that were followed were in accordance with the Helsinki Declaration of 1975.

The diagnosis of HBV infection was based on the quantitation of HBV DNA by qPCR and examination of liver biopsy samples. Quantitative assessment of HBV DNA was performed using COBAS $^{\circledR}$ AmpliPrep/COBAS $^{\circledR}$ TaqMan $^{\circledR}$ System (Roche).

Liver biopsy. Liver biopsies were taken prior to the treatment as part of the routine care standard for the subjects. The biopsy specimens were evaluated by an

e-mail: camilaw@tlen.pl

Abbreviations: GFER1, Growth factor erv1-like; HBV, hepatitis B virus; $\mathrm{HO}-1$, hemoxygenase; HMOX-1, hemeoxygenase (decycling)-1; $\mathrm{NQO1}$, NAD(P)H:quinone oxidoreductase-1 
experienced pathologist. The grade of inflammation and the state of fibrosis were assessed according to the Batts and Ludwig scale.

Real-Time PCR was used to evaluate the HMOX-1, NQO1, GFER1 and miR-122 expression in the liver biopsy samples.

Total RNA isolation. The mirVana ${ }^{\mathrm{TM}}$ miRNA isolation kit (Ambion)was used to isolate total RNA according to the manufacturer's procedure. Frozen samples were homogenized in $300 \mu \mathrm{L}$ of the Lysis/Binding Solution using a TissueRuptor homogenizer (Qiagen). RNA was eluted with $100 \mu \mathrm{L}$ of RNase-free water. Total RNA concentrations and quality were determined by spectrophotometry. The quality of RNA samples was measured by the ratio of absorptions at $260 / 280 \mathrm{~nm}$. Purified total RNA was used immediately for cDNA synthesis or stored at $-80^{\circ} \mathrm{C}$.

miRNA-122 expression. RT-qPCR analysis was used to determine the relative expression level of miR-122.

Reverse transcription was performed with $10 \mathrm{ng}$ of total RNA in $15 \mu$ reactions using the TaqMan ${ }^{\circledR}$ MicroRNA Reverse Transcription Kit (Applied Biosystems), according to the manufacturer's guidelines. The RT reaction was diluted 10 times in nuclease-free water and $9 \mu \mathrm{L}$ aliquots were subsequently used for PCR amplification using the TaqMan ${ }^{\circledR}$ MicroRNA Assays (miR122-Assay ID 002130, RNU 24-Assay ID 001001), according to the manufacturer's instructions (Applied Biosystems). RNU 24 (SNORD24 small nucleolar RNA, C/D box 24) was used as an endogenous control.

mRNA expression. HMOX-1, GFER1 and NQO1 mRNA expression was determined by the homo sapiensspecific TaqManGene Expression Assay (Applied Biosystems). cDNA generation was performed using $250 \mathrm{ng}$ of total RNA with High Capacity cDNA Reverse Transcription Kits, according to the manufacturer's protocols (Applied Biosystems). Synthesized first-strand cDNA was diluted ten times in nuclease-free water before addition to the RT-PCR reaction mixture. mRNA expression levels were analysed using beta actin (ACTB) as an endogenous control.

Real-Time PCR analysis. TaqMan PCR assays were performed in 96-well optical plates with a 7900HT Fast Real-Time PCR System (Applied Biosystems) and were analysed using the Sequence Detection System 2.0 Software. Fold induction values were calculated according to the equation: $2 \Delta \Delta \mathrm{Ct}$, where $\Delta \mathrm{Ct}$ defines the differences in cycle threshold numbers between the target gene and endogenous control, and $\Delta \Delta C$ t represents the relative change in these differences between the examined groups and controls.

Statistical analysis. Quantitative data was expressed as median and range. The Shapiro-Wilk test was used to confirm whether the distribution was normal. Normally-distributed variables were compared with the Student's $t$-test, and non-normally distributed variables with the Mann-Whitney U-test. Correlations between the hepatic expression of antioxidant genes HMOX-1, GFER1, NQO1 and miR-122 were measured with the Spearman rank correlation coefficient. $P$-values $<0.05$ were considered to be statistically significant. All statistical analyses were performed using Statistica software version 10.0.

\section{RESULTS}

Thirty-four individuals with chronic hepatitis B were included in this study, of whom nine were women and
Table 1. Characteristics of the study group

\begin{tabular}{|c|c|c|}
\hline & \multicolumn{2}{|c|}{ HBV infection $(n=34)$} \\
\hline & LQ-UQ & MEDIAN (min-max) \\
\hline Age (years) & $23-41.5$ & $29.5(20-46)$ \\
\hline ALT U/I & $25-54$ & $37(15-234)$ \\
\hline \multirow[t]{2}{*}{$\begin{array}{l}\text { HBV-DNA } \\
\text { copies/ml }\end{array}$} & $\begin{array}{l}15464- \\
333899\end{array}$ & $\begin{array}{l}54007(116- \\
582447674)\end{array}$ \\
\hline & $\begin{array}{l}\text { Number of } \\
\text { patients }\end{array}$ & $\begin{array}{l}\text { Fraction } \\
\%\end{array}$ \\
\hline Age $<40$ years & 26 & 76.47 \\
\hline Age $\geq 40$ years & 8 & 23.53 \\
\hline Women & 9 & 26.47 \\
\hline Men & 25 & 73.53 \\
\hline $\begin{array}{l}\text { HBV-DNA } \\
<10000 \\
\text { copies/ml }\end{array}$ & 10 & 29.41 \\
\hline $\begin{array}{l}\text { HBV-DNA } \\
\geq 10000 \\
\text { copies/ml }\end{array}$ & 24 & 70.59 \\
\hline \multicolumn{3}{|c|}{$\begin{array}{l}\text { Assessment of liver biopsy samples according to the Batts and } \\
\text { Ludwig scale }\end{array}$} \\
\hline Grading 0 & 12 & 35 \\
\hline Grading 1 & 17 & 50 \\
\hline Grading 2 & 4 & 12 \\
\hline Grading 3 & 1 & 3 \\
\hline Grading 4 & 0 & 0 \\
\hline Staging 0 & 0 & 0 \\
\hline Staging 1 & 13 & 39 \\
\hline Staging 2 & 20 & 59 \\
\hline Staging 3 & 1 & 2 \\
\hline Staging 4 & 0 & 0 \\
\hline
\end{tabular}

twenty-five were men. The median age of patients was 29.5 years with a range from 20 to 46 years (LQ 22 years-UQ 41.5 years). All patients underwent hepatitis $\mathrm{B}$ antigen seroclearance. Patient characteristics are presented in Table 1.

\section{HBV-DNA and hepatic expression of HMOX-1, NQO1, GFER1, and miR-122}

The median plasma HBV viremia was 54007 cop$\mathrm{ies} / \mathrm{ml}$ (LQ 15464 copies/ml-UQ 333899 copies/ $\mathrm{ml})$. Furthermore, HBV viral loads were found to be associated with liver inflammation $(p=0.0006)$ and fibrosis $(p=0.01)$ (Table 2 and Table 3). Hepatic expression of HMOX-1, NQO1, GFER1 and miR-122 was not correlated with HBV-DNA level (Table 4). 
Table 2. Hepatic expression of HMOX-1, GFER1, NQO1, miR-122 and HBV-DNA depending on the liver inflammation

\begin{tabular}{llllll}
\hline & Grading $<2(\mathrm{n}=29)$ & & Grading $\geq 2(\mathrm{n}=5)$ & $\mathrm{p}$-value \\
\hline & Median (LQ-UQ) & Min-Max & Median (LQ-UQ) & Min-Max & $\mathrm{p}$ \\
\hline miR-122 & $7.70(5.84-9.36)$ & $2.99-31.73$ & $4.31(2.91-6.45)$ & $1.53-26.61$ & $>0.05$ \\
\hline HMOX-1 & $46.56(26.50-79.67)$ & $1.64-386.14$ & $15.93(13.94-25.74)$ & $10.97-46.39$ & 0.04 \\
\hdashline GFER1 & $2.53(1.87-3.64)$ & $0.28-12.95$ & $1.92(1.43-3.17)$ & $0.69-3.75$ & $>0.05$ \\
\hdashline NQO1 & $1.66(0.42-2.79)$ & $0.06-29.26$ & $0.80(0.42-1.55)$ & $0.14-2.95$ & $>0.05$ \\
\hdashline HBV-DNA copies/ml & $39634(12158-221503.5)$ & $116-582434674$ & $6867600(5745017-6867600)$ & $333899-15364800$ & 0.0006 \\
\hline
\end{tabular}

HMOX-1 (hemeoxygenase-1), GFER1(Growth factor erv1-like), NQO1 (NAD(P)H:quinone oxidoreductase-1)

Table 3. Hepatic expression of HMOX-1, GFER1, NQO1, miR-122 and HBV-DNA depending on liver fibrosis

\begin{tabular}{llllll}
\hline & \multicolumn{1}{l}{ Staging<2 $(\mathrm{n}=13)$} & & Staging $\geq 2(\mathrm{n}=21)$ & & $\mathrm{p}$-value \\
\hline & Median (LQ-UQ) & Min-Max & Median (LQ-UQ) & Min-Max & $\mathrm{p}$ \\
\hline miR-122 & $6.40(4.76-8.21)$ & $1.53-26.61$ & $7.83(6.44-10.69)$ & $3.32-31.73$ & $>0.05$ \\
\hdashline HMOX-1 & $33.36(21.56-69.45)$ & $1.64-285.23$ & $35.70(21.21-89.51)$ & $2.78-386.14$ & $>0.05$ \\
\hline GFER1 & $2.37(1.74-3.53)$ & $0.29-12.95$ & $3.43(1.87-3.91)$ & $0.47-7.39$ & $>0.05$ \\
\hline NQO1 & $0.97(0.38-2.24)$ & $0.06-5.57$ & $2.44(1.21-3.97)$ & $0.12-29.26$ & 0.035 \\
\hline HBV-DNA copies/ml & 21621,5 & & & & \\
& $(2034-303129)$ & $116-303129$ & $99441(36084-5745015$ & $780-582447674$ & 0.01 \\
\hline
\end{tabular}

HMOX-1 (hemeoxygenase-1), GFER1(Growth factor erv1-like), NQO1 (NAD(P)H:quinone oxidoreductase-1)

\section{Hepatic expression of HMOX-1, NQO1, GFER1, and miR-122 in the context of liver injury}

Assessment of liver inflammation and fibrosis based on liver biopsy samples was performed in all patients. Due to the limited group of patients included in this study, the subjects were divided into two subgroups for the sake of statistical analysis: one group of 22 patients in whom necroinflammatory activity (grade $\geq 1$ ) in liver biopsy specimens was reported, and another of 12 patients who did not demonstrate any inflammation in the liver tissue (grade 0). Among subjects with the necroinflammatory activity, mild inflammation (grade 1) was reported in 17 patients. However, grade 2 inflammation was described only in 4, and grade 3 inflammation only in 1 patient. Lower hepatic expression of HMOX-1 was found to correlate with the greater severity of liver inflammation $(p=0.04)$. However, the hepatic expression of GFER1, NQO1 and miR-122 was not related to the necroinflammatory activity (Table 2 ).

Severe fibrosis $(\mathrm{S} \geq 2)$ was detected in 21 patients. Again, the hepatic expression of HMOX-1, GFER1 and miR-122 did not correspond to the severity of the liver fibrosis. However, the liver biopsy specimens of patients with advanced fibrosis demonstrated a significantly higher expression of NQO1 ( $\mathrm{p}=0.035)$ (Table 3).

\section{Correlation between the hepatic expression of HMOX-1, GFER1, NQO1 and miR-122}

A significant positive association was found between the hepatic expression of NQO1 and miR-122 $(p=0.039)$. In addition, an insignificant relationship was found between the higher expression of HMOX-1 and
GFER1, and the expression of miR-122 ( $\mathrm{p}=0.07$ and $\mathrm{p}=0.68)$ (Table 5).

\section{DISCUSSION}

HBV viral loads were found to have a significant impact on the liver inflammation and fibrosis in patients with chronic hepatitis B. Similarly to Iloeje and coworkers (2006) this study shows that advanced fibrosis in the hepatitis B-infected people is strongly associated with higher levels of the circulating virus. Numerous studies have suggested that miRNAs are involved in the liver fibrogenesis through signalling of the transforming growth factor beta (TGF- $\beta$ ) and nuclear factor kappa B (NFxB) (Roderburg et al., 2011; Zhang et al., 2012). However, the study presented here does not confirm these findings: our results indicate that hepatic expression of miR-122 in HBV patients does not reflect the liver inflammation level and fibrosis. Similar results were obtained by Xing et al. who found no statistically significant difference in the serum levels of miR-122 between chronic HBV carriers and subjects with liver cirrhosis (Xing et al., 2014).

To assess whether miR-122 can indeed be involved in the antioxidant response, the relationship between the hepatic expression of miR-122 and the aforementioned antioxidant genes was examined more closely. Our gene expression study revealed a positive correlation between miR-122 and NQO1 in human liver biopsies obtained from $\mathrm{HBV}$-infected patients. It may be possible that miR-122 indirectly limits the oxidative stress by suppression of the HBV replication and as a consequence affects the balance between the pro-oxidants and antioxidants. A significantly greater expression of HMOX-1 
Table 4. Correlations between the expression of HMOX-1, GFER1, NQO1, miR-122 and HBV-DNA

\begin{tabular}{|c|c|c|c|c|c|c|c|c|}
\hline & HMOX-1 & & GFER1 & & NQO1 & & MiR-122 & \\
\hline & $\begin{array}{l}\text { Spearman's } \\
\text { rank correlation } \\
\rho\end{array}$ & p-value & $\begin{array}{l}\text { Spearman's } \\
\text { rank correlation } \\
\rho\end{array}$ & p-value & $\begin{array}{l}\text { Spearman's } \\
\text { rank correlation } \\
\rho\end{array}$ & $p$-value & $\begin{array}{l}\text { Spearman`s rank } \\
\text { correlation } \\
\rho\end{array}$ & $\mathrm{p}$-value \\
\hline HBV-DNA & 0.09 & $>0.05$ & 0.07 & $>0.05$ & 0.14 & $>0.05$ & 0.24 & $>0.05$ \\
\hline
\end{tabular}

Table 5. Correlations between the hepatic expression of HMOX-1, GFER1, NQO1 and miR-122

\begin{tabular}{|c|c|c|c|c|c|c|}
\hline & HMOX-1 & & GFER1 & & NQO1 & \\
\hline & $\begin{array}{l}\text { Spearman`s rank } \\
\text { correlation } \\
\rho\end{array}$ & p-value & $\begin{array}{l}\text { Spearman`s rank } \\
\text { correlation } \\
\rho\end{array}$ & $p$-value & $\begin{array}{l}\text { Spearman`s rank } \\
\text { correlation } \\
\rho\end{array}$ & $p$-value \\
\hline miR-122 & 0.31 & $>0.05(0.07)$ & 0.08 & $>0.05$ & 0.36 & 0.039 \\
\hline
\end{tabular}

was observed in patients with low grade liver inflammation. It is well known that the antioxidant enzymes, such as HO-1 (heme oxygenase 1), encoded by HMOX-1, or $\mathrm{NAD}(\mathrm{P}) \mathrm{H}$ quinone oxidoreductase 1 (NQO1), may play a crucial role by protecting the cells against oxidative stress and suppressing inflammation. HO-1 is responsible for catalysing breakdown of the haem into equimolar concentrations of carbon monoxide (CO), biliverdin, and iron (Wunder et al., 2003). CO may possess anti-inflammatory properties, such as the capacity to inhibit platelet aggregation and the expression of pro-inflammatory cytokines (Wunder et al., 2003; Maines et al., 1997).

Interestingly, $\mathrm{NAD}(\mathrm{P}) \mathrm{H}$ quinone oxidoreductase 1 (NQO1) is a cytosolic flavoprotein that is also capable of scavenging superoxide anions generated during oxidative stress, and regenerating the reduced forms of protective endogenous antioxidant compounds (Siegel et al., 2000). In a recently conducted study, Cheng and coworkers (2015) noted an increased expression of NQO1 in hepatocellular carcinoma, alcoholic cirrhosis and HBV-related cirrhosis, when compared with normal liver tissues. These results agree with our present findings which indicate a significantly higher hepatic expression of NQO1 in HBV-infected patients with advanced fibrosis. However, in the study presented here, the hepatic expression of GFER1, encoding Augmenter of Liver Regeneration (ALR) which has a beneficial effect on the process of liver regeneration, was not associated with severity of the hepatic inflammation and fibrosis in patients chronically infected with HBV. Interestingly, Tanigawa and coworkers (2000) had demonstrated in a rat model that ALR may induce liver regeneration by inhibition of the hepatic natural killer cell activity in the case of acute liver injury. ALR can also reverse the hepatic fibrosis by inhibiting the metallopeptidase inhibitor 1 (TIMP-1) expression, a natural inhibitor of the matrix metalloproteinases (MMPs), i.e. a group of peptidases involved in degradation of the extracellular matrix in pathologic liver tissue (Li et al., 2005).

The limitations of this study are its small group of subjects and the lack of comparison to healthy controls. Furthermore, the somewhat ambiguous nature of the results obtained from this analysis indicates that further studies are needed to precisely clarify the role of the antioxidant response and miR-122 in pathogenesis of chronic hepatitis $\mathrm{B}$.

In conclusion, liver injuries in chronic hepatitis B may be associated with the hepatic expressions of HMOX1 and NQO1. However, hepatic expression of miR-122 does not seem to correspond with progression of the liver disease

\section{Disclosure}

The authors report no conflict of interest.

\section{REFERENCES}

Chen G, Lin W, Shen F, Iloeje UH, London WT, Evans AA (2006) Past HBV viral load as predictor of mortality and morbidity from $\mathrm{HCC}$ and chronic liver disease in a prospective study. Am J Gastroenterol 101: 1797-1803.

Cheng ML, Lu YF, Chen H, Shen ZY, Liu J (2015) Liver expression of Nrf2-related genes in different liver diseases. Hepatobiliary Pancreat Dis Int 14: 485-491.

Chisari FV, Isogawa M, Wieland SF (2010) Pathogenesis of hepatitis B virus infection. Pathol Biol (Paris) 58: 258-266. doi: 10.1016/j.patbio.2009.11.001.

Guidotti LG, Chisari FV (2006) Immunobiology and pathogenesis of viral hepatitis. Annu Rev Pathol 1: 23-61.

Iloeje UH, Yang HI, Su J, Jen CL, You SL, Chen CJ; Risk Evaluation of Viral Load Elevation and Associated Liver Disease/Cancer-In HBV (the REVEAL-HBV) Study Group (2006) Predicting cirrhosis risk based on the level of circulating hepatitis B viral load. Gastroenterology 130: 678-686.

Li Q, Liu DM, Zhang LM, Zhu B, He YT, Xiao YH (2005) Effects of augmentation of liver regeneration recombinant plasmid on rat hepatic fibrosis. World J Gastroenterol 8: 2438-2443.

Maines MD (1997) The heme oxygenase system: a regulator of second messenger gases. Annu Rev Pharmacol Toxicol 37: 517-554.

Qiu L, Fan H, Jin W, Zhao B, Wang Y, Ju Y, Chen L, Chen Y, Duan Z, Meng S (2010) miR-122-induced down-regulation of HO-1 negatively affects miR-122-mediated suppression of HBV. Biochem Biophys Res Commun 6: 771-777. doi: 10.1016/j.bbrc.2010.07.021.

Protzer U, Seyfried S, Quasdorff M, Sass G, Svorcova M, Webb D, Bohne F, Hösel M, Schirmacher P, Tiegs G (2007) Antiviral activity and hepatoprotection by heme oxygenase- 1 in hepatitis B virus infection. Gastroenterology 133: 1156-1165.

Roderburg C, Urban GW, Bettermann K, Vucur M, Zimmermann H, Schmidt S, Janssen J, Koppe C, Knolle P, Castoldi M, Tacke F, Trautwein C, Luedde T (2011) Micro-RNA profiling reveals a role for miR-29 in human and murine liver fibrosis. Hepatology 53: 209218. doi: $10.1002 /$ hep. 23922 .

Siegel D, Ross D (2000) Immunodetection of NAD(P)H:quinone oxidoreductase 1 (NQO1) in human tissues. Free Radic Biol Med 29: 246-253.

Tanigawa K, Sakaida I, Masuhara M, Hagiya M, Okita K (2000). Augmenter of liver regeneration (ALR) may promote liver regeneration by reducing natural killer $(\mathrm{NK})$ cell activity in human liver diseases. I Gastroenterol 35: 112-119.

Tasdelen Fisgin N, Aydin BK, Sarikaya H, Tanyel E, Esen S, Sunbul M, Leblebicioglu H (2012) Oxidative stress and antioxidant defense in patients with chronic hepatitis B. Clin Lab 58: 273-280.

Wang S, Qiu L, Yan X, Jin W, Wang Y, Chen L, Wu E, Ye X, Gao GF, Wang F, Chen Y, Duan Z, Meng S (2012) Loss of microRNA 122 expression in patients with hepatitis B enhances hepatitis B virus replication through cyclin $\mathrm{G}(1)$-modulated P53 activity. Hepatology 55: 730-741. doi: 10.1002/hep.24809. 
Waris G, Huh KW, Siddiqui A (2001) Mitochondrially associated hepatitis $\mathrm{B}$ virus $\mathrm{X}$ protein constitutively activates transcription factors STAT-3 and NF-kappa B via oxidative stress. Mol Cell Biol 21: 7721-7730.

World Health Organization (2000) Hepatitis B.

Wunder C, Potter RF (2003) The heme oxygenase system: its role in liver inflammation. Curr Drug Targets Cardiovasc Haematol Disord 3: 199-208.
Xing TJ, Jiang DF, Huang JX, Xu ZL (2014) Expression and clinical significance of miR-122 and miR-29 in hepatitis B virus-related liver disease. Genet Mol Res 29: 7912-7918. doi: 10.4238/2014.

Zhang H, Li QY, Guo ZZ, Guan Y, Du J, Lu YY, Hu YY, Liu P, Huang S, Su SB (2012) Serum levels of microRNAs can specifically predict liver injury of chronic hepatitis B. World J Gastroenterol 7: 5188-5196. doi: 10.3748/wjg.v18.i37.5188. 